\title{
Biodiversidade amazônica em materiais de divulgação científica com ênfase para o ensino de Ciências
}

\author{
Amazonian biodiversity in scientific dissemination materials with \\ emphasis on science teaching
}

\author{
lara Maíra Moraes de Andrade ${ }^{1}\left(\mathbb{0}\right.$, Elizandra Rego de Vasconcelos ${ }^{1}(\mathbb{1}$ \\ ' Universidade Federal do Amazonas, Manaus, AM, Brasil
}

\section{RESUMO}

A pesquisa teve por objetivo: estudar materiais de divulgação cientifica em diferentes meios de veiculação social. Além disso, analisar meios de divulgação científica que abordem o tema da biodiversidade amazônica. O estudo possui natureza qualitativa, pois trata-se de um estudo exploratório, o qual ocupa-se da descrição e contextualização do objeto de estudo. O método de investigação foi a pesquisa documental com análise de conteúdo. Os resultados demonstram que os meios de Divulgação científica têm variado de acordo com as transformações sociais. E que o uso de mídias de áudio (Podcast) e áudio visuais (Canais no YouTube) tem crescido e, revelado um espaço de veiculação de informações sobre ciência que alcança um público mais amplo.

Palavras-chave: Divulgação Científica; Biodiversidade; Mídias

\section{ABSTRACT}

The objective of the research was to study scientific dissemination materials in different media. And yet, analyze means of scientific dissemination that address the theme of Amazonian biodiversity. The study has a qualitative nature, as it's an exploratory study, which deals with the description and contextualization of the study's object. The method of investigation was documentary research with content analysis. The results demonstrate that the DC media has varied according to social transformations. And the use of audio media (PodCast) and audiovisual (Channels on YouTube) has grown and revealed a space for the dissemination of information about science that reaches a broader audience.

Keywords: Scientific divulgation; Biodiversity; Media 


\section{INTRODUÇÃO}

A sociedade atual encontra-se em uma crise humanitária de acesso aos serviços de saúde e saneamento básico, a qual foi potencializada com pandemia de SARS COV2. "A questão da credibilidade científica configura-se, para nós, como uma boa entrada para uma discussão sobre a dramática cena planetária" (CARVALHO; CARVALHO, 2020, p.1). Nestes dias, a ciência tem se tornado protagonista nas discussões sobre o enfrentamento de problemas e compreensão da realidade.

Ao mesmo tempo, vive-se um tempo de maior questionamento das verdades científicas, tais como: efetividade/funcionalidade das vacinas, terra esférica, dentre outras. Este cenário sinaliza a necessidade de tornar temas científicos mais populares (MARINELI, 2020; PIVARO; JÚNIOR, 2020).

[...] o negacionismo científico começou a ser utilizado como forma de manipulação da opinião pública pela indústria por motivos econômicos e, obtendo sucesso, suas táticas foram reproduzidas quando necessárias por outras corporações. Utilizando os meios midiáticos para a implementação da dúvida de uma ausência de consensos científicos no imaginário coletivo, os debates acerca dos resultados científicos tornaram se uma questão de opinião guiada por uma polarização política (PIVARO; JúNIOR, 2020, p. 1076).

Nesse contexto, a Divulgação Científica (DC) ganha destaque na sociedade. É considerada um meio para diminuir o distanciamento entre o conhecimento científico e a população geral. A Divulgação Científica permite que pesquisas e trabalhos de origem científica e/ou tecnológica possam ser acessados e compreendidos pela população em geral. E pode ocorrer por diferentes meios, tais como, traduções, ilustrações, recursos visuais, eventos, feiras, entre outros (FRANÇA, 2015).

Nascimento $(2015$, p. 161) apresenta a divulgação científica como “[...] toda prática de comunicação da cultura científica e tecnológica fora dos círculos dos especialistas e dos quadros formais de ensino". Já Capozoli (2002, p. 121-4), conceitua a DC como "[...] um esforço de inteligibilidade do mundo que se busca e, 
ao mesmo tempo, se compartilha com os demais". O grande desafio, refere-se a explicitar com clareza do que se trata a ciência. De acordo com os autores os textos de DC são capazes de construir um conhecimento científico da mesma forma que uma pesquisa científica, pois está relacionado a questão de interpretação, que desta forma revela um mundo novo.

Na educação científica (formal e informal) os textos de DC são sugeridos como material complementar a serem usados de forma lúdica e criativa "[...] utilizando-se de recursos, técnicas, processos e produtos (veículos ou canais) para a veiculação de informações científicas, tecnológicas ou associadas a inovações ao público leigo" (BUENO, 2009, p.162). Isto funda-se na importância das práticas de ensino que, além de facilitar a inclusão do conhecimento científico em hábitos e atitudes em uma sociedade.

Ao discutir sobre o papel social da DC, Bueno (2010, p. 5) considera que "[...] a divulgação científica contribui com a inclusão do debate sobre temas especializados e de impacto na vida do indivíduo". Permite que pessoas 'leigas' assimilem novas descobertas e se inteirem sobre o progresso científico. Isto contribui para a compreensão do mundo em que vivem.

Nesse momento histórica a DC tornou-se uma necessidade cada vez mais pungente. Para Massarani (2021, p. 282) a DC é um dever dos cientistas na atualidade "[...] o cientista deve atender a este dever direta ou indiretamente, no último caso em uma estreita colaboração com os jornalistas leigos. Não basta fazer ciência é preciso propala-la.

No Brasil, o ano de 2020, foi considerado dramático não só pelas consequências decorrentes da pandemia de covid 19, mas pela ampla degradação ambiental que já ocorre há anos. Segundo a Organização das Nações Unidas (ONU) enfrenta-se atualmente uma perda de biodiversidade sem precedentes na história.

Apesar da biodiversidade ser um tema conhecido, nem sempre ele é compreendido em sua complexidade. A literatura científica, utiliza uma linguagem complicada para o cidadão comum distinguir e atribuir valores. Nesse sentido, os 
textos de DC auxiliam o cidadão, fazendo-o relacionar a biodiversidade com o seu cotidiano.

Diante disso, faz-se necessário a promoção da ciência por meio da DC. Hoje, a ciência veicula na sociedade por meios digitais, impressos, audiovisuais etc. E isso, seguramente tem contribuído para compreensão da ciência pela população em geral.

Neste sentido, essa pesquisa teve por objetivo: estudar materiais de divulgação cientifica em diferentes meios de veiculação social. E ainda, analisar meios de divulgação científica que abordem o tema da biodiversidade amazônica.

\section{PROCEDIMENTOS METODOLÓGICOS}

A pesquisa tem objetivos de caráter descritivo e exploratório, seguindo uma abordagem quali-quantitativa, pois trata-se de um estudo exploratório, o qual ocupa-se da descrição e contextualização do objeto de estudo. A pesquisa foi realizada por meio de uma pesquisa documental em revistas/materiais de DC no período de 1999-2020. A escolha dessa modalidade é por consistir em uma “[...] técnica de abordagem dos dados qualitativos". E que pode complementar informações obtidas por outras técnicas, desvendando outros aspectos importantes do tema (LÜDKE; ANDRÉ, 2013 p. 03).

A análise aconteceu em três etapas. Leitura de materiais de DC sobre biodiversidade, pertencentes a três categorias, sendo estas: material impresso, audiovisual e veiculados em meio digital gratuitamente. A partir dessa leitura, selecionou-se materiais com potencial para o público escolar (infanto juvenil). Segundo Dubrull e e Deccache-Maia (2021, p. 7);

[...] a divulgação científica é realizada por meio de uma série de atividades gratuitas e acessíveis ao público em geral como, por exemplo, visitas orientadas às exposições fixas e temporárias, cursos de curta duração, observação do céu em telescópio, oficinas temáticas e palestras sobre assuntos científicos. 
Os critérios de seleção dos materiais foram os seguintes: origem brasileira, com idioma português, disponível gratuitamente e contemplar o tema biodiversidade brasileira e amazônica, conforme avaliação da credibilidade de cada material relevante para a pesquisa (CELLARD, 2008). Dentre os critérios citados, a gratuidade do material foi prioritária, pois entende-se que a dimensão financeira é um dos principais entraves para o acesso da sociedade a materiais sobre temas científicos.

Desse modo, a amostra do material selecionado para pesquisa, é, de caráter não probabilístico, pois a seleção dos materiais da pesquisa foi feita com materiais acessíveis (gratuitos e, principalmente, disponíveis em formato digital em virtude das recomendações sanitárias impostas pela pandemia de covid 19) para as pesquisadoras (MALHOTRA, 2019).

Após a seleção dos materiais de DC, realizou-se a análise do conteúdo de acordo com as categorias a priori apresentadas por Souza e Rocha (2017), sendo estas: conceitos e definições, explicação dos termos desconhecidos, público alvo, influência/relação com ambiente, linguagem acessível e aspectos que atraem atenção.

\section{RESULTADOS E DISCUSSÕES}

A ciência é estereotipada como um conhecimento restrito a pessoas com capacidades intelectuais mais favorecidas em detrimento do público geral. Essa ideia, percebida na história da ciência desde sua origem é uma das razões pelas quais a sociedade geral associou, em seu senso comum, a atividade científica com algo difícil e, para poucos considerados "gênios".

Os conhecimentos científicos aparecem como obras de gênios isolados, ignorando-se o papel do trabalho coletivo e cooperativo, dos intercâmbios entre equipes. [...] Muitas vezes insiste-se explicitamente em que o trabalho científico é um domínio reservado a minorias especialmente dotadas, transmitindo-se assim expectativas negativas à maioria dos alunos, com claras discriminações de natureza social e sexual (GIL PÉREZ. Et Al, 2001, P. 133). 
Essa característica histórica conduziu a um afastamento paulatino da sociedade das temáticas científicas. Inclusive, quando esta mostra-se necessária. Com um movimento de democratização da ciência observado nos últimos anos, tem crescido o surgimento de materiais de divulgação científica. A ideia é apresentar a ciência enquanto atividade, sobretudo, humana e movida pelas demandas oriundas da vida cotidiana. Nessa pesquisa, encontrou-se um total de doze (12) materiais de DC, os quais foram analisados de acordo com seu meio de veiculação e objetivos.

Figura 1 - Diferentes meios de veiculação da DC

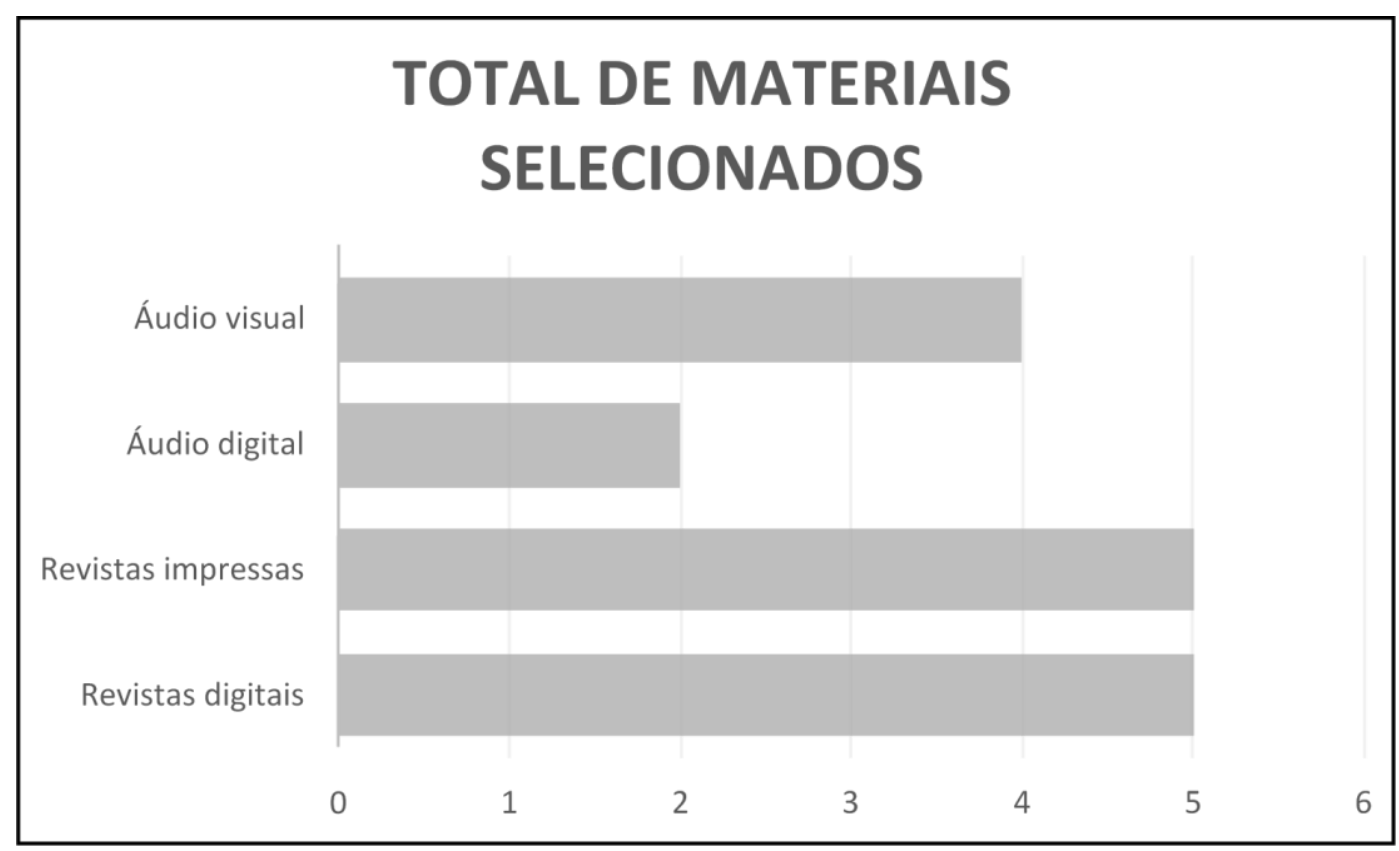

Fonte: Organização das autoras

Percebe-se que as revistas digitais e impressas aparecem em igual número e majoritário. Isto se deve a ampliação do mercado digital nos últimos vinte anos.

“O desenvolvimento dos computadores inverte a relação tamanho versus quantidade, porquanto as memórias são cada vez menores em tamanho, enquanto estocam quantidades de informação cada vez maiores" (GARCIA; SOUSA, 2011, p. 80). Trata-se de uma tendencia de mercado que considera a inovação, conservação ambiental e adequação destes produtos as práticas sociais contemporâneas. 
[...] o consumo de uma imensa quantidade de imagens já se tornou prática regular, e muitas pessoas já acordam olhando para imagens nas pequenas telas dos seus celulares, vemos também que as inundações de imagens que nos chegam diariamente acabam por nos colocar em situações antes vividas tendo aparelhos de televisão ligados o dia inteiro (Hoffmann, 2021, p. 57).

No tempo atual a informação está na "palma da mão" ou em um 'clic'. Isto é uma característica da cultura atual, na qual as tecnologias contribuem para dinamizar a vida a organização social (2011). Isso influencia a maneira como as pessoas lidam com o conhecimento, especialmente no campo educacional.

Nessa perspectiva, à medida que o processo de compreensão do papel da educação, no contexto da cibercultura, toma forma objetiva em projetos didáticos próprios, o professor vai assumindo outra posição e descobrindo novas formas para o seu fazer pedagógico" (GARCIA; SOUSA, 2011, p. 85).

A migração das revistas de DC para o ambiente virtual são um resultado dessa cibercultura. Mais recentemente, também vem crescendo o mercado de veículos de comunicação audiovisual em plataformas digitais (SILVA; PEREIRA, 2021). Principalmente, com os apelos de uma sociedade cada vez mais voltada para o lucro e produtividade.

O contexto de Cibercultura e Inteligência Artificial apresenta se como possibilitador de divulgação científica [...]. Os múltiplos meios de comunicação permitem inúmeras formas de divulgação através de hipertextos e textos escritos, orais, visuais e audiovisuais veiculados na rede mundial de computadores e visualizados em dispositivos móveis. [...] a Cibercultura e a Inteligência Artificial se constituem espaço-tempo valiosos para a divulgação da Ciência (CONCEIÇÃO; CHAGAS, 2020, p. 3).

A temática científica em veículos digitais atende a necessidade da sociedade geral contempla o público jovem de nativos digitais, para os quais o tempo entre a pergunta e a informação tende a ser mínimo. De acordo com Tocantins e Wiggers (2021) As constantes mudanças no cenário social e perfis tecnológicos tem implicações diretas sobre a cultura global e na vida das pessoas. Isto demanda novos olhares sobre a comunicação social, acadêmica e escolar.

Blum, Dias, Filho (2021) referem-se a mídias como a televisão, internet, computadores e celulares como "excitantes sociais" que dinamizam as relações sociais humanas. Não há mais como negar as plataformas digitais como caminho 
a ser explorado no campo comunicativo e interacional. As tecnologias digitais permeiam a vida cotidiana de tal modo que não é possível considerar a dinâmica social sem a sua presença e influência. O uso individualizado da Internet no celular/tablets, dissolve dificuldades de tempo e espaço quando o assunto é acesso a discussão de temas científicos (TOCANTINS; WIGGERS, 2021).

[...] a presença ou o uso das TIC na vida cotidiana não implica necessariamente apropriação, mas indica uma trajetória, um processo, que pode ou não culminar em apropriação. Apropriar-se de uma determinada tecnologia vai muito além de ter acesso a ela ou, simplesmente, utilizá-la em algumas situações. Nessa concepção, seria possível uma pessoa ter acesso, usar e não se apropriar. Por outro lado, a apropriação pode desdobrar-se em diversos modos, como em processos de reprodução ou ressignificação (Tocantins e Wiggers, 2021, p. 76).

Os materiais da tabela 1 foram selecionados por tratarem do tema biodiversidade e apresentarem-se nas modalidades, impressa e digital, gratuitamente.

Tabela 1 - Revistas de DC selecionadas para pesquisa documental

\begin{tabular}{|c|c|c|c|c|}
\hline Título & Tempo no mercado & Objetivo & $\begin{array}{c}\text { Meio de } \\
\text { divulgação }\end{array}$ & Público alvo \\
\hline $\begin{array}{l}\text { Revista } \\
\text { Ciência Hoje }\end{array}$ & 30 anos & Divulgação científica & $\begin{array}{c}\text { Mídia impressa e } \\
\text { Digital }\end{array}$ & $\begin{array}{c}\text { crianças, Jovens } \\
\text { e adultos }\end{array}$ \\
\hline $\begin{array}{l}\text { Revista } \\
\text { Pesquisa } \\
\text { FAPESP }\end{array}$ & 20 anos & $\begin{array}{l}\text { Difundir e valorizar } \\
\text { os resultados da } \\
\text { produção científica e } \\
\text { tecnológica } \\
\text { brasileira. }\end{array}$ & $\begin{array}{l}\text { Mídia impressa, } \\
\text { Áudio e Digital }\end{array}$ & $\begin{array}{l}\text { Jovens e } \\
\text { adultos }\end{array}$ \\
\hline $\begin{array}{l}\text { Revista } \\
\text { Galileu }\end{array}$ & 30 anos & $\begin{array}{c}\text { Comunicação } \\
\text { midiática para } \\
\text { divulgar assuntos } \\
\text { que envolvem ciência } \\
\text { e tecnologia }\end{array}$ & $\begin{array}{c}\text { Mídia impressa e } \\
\text { Digital }\end{array}$ & $\begin{array}{l}\text { Jovens e } \\
\text { adultos }\end{array}$ \\
\hline $\begin{array}{l}\text { Revista } \\
\text { Mundo Jovem }\end{array}$ & 54 anos & $\begin{array}{l}\text { Inovar na divulgação } \\
\text { cientifica ao fazer uso } \\
\text { de uma linguagem } \\
\text { simples e direta }\end{array}$ & $\begin{array}{c}\text { Mídia impressa e } \\
\text { Digital }\end{array}$ & $\begin{array}{l}\text { Jovens e } \\
\text { adultos }\end{array}$ \\
\hline
\end{tabular}

Fonte: Organização das autoras 
Após seleção, os materiais foram divididos em categorias por mídia, sendo elas: mídias digitais, impressas e áudio visuais, conforme anexo 1. Abordar o tema biodiversidade foi um dos critérios de seleção dos materiais analisados.

Para a Organização das Nações Unidas (1992), a biodiversidade é entendida como sendo a variedade de seres vivos da Terra, fruto de bilhões de anos de evolução. Possível por meio dos processos de seleção natural e, de uma forma cada vez mais acentuada, pelas atividades humanas.

A ação antrópica ocasionou a diminuição de $20 \%$ na abundância média de espécies nativas na maioria dos habitats terrestres, e, cerca de $66 \%$ do ambiente marinho foram significativamente alterados pelas ações humanas. As áreas urbanas mais que dobraram e a poluição plástica aumentou dez vezes durante os últimos 20 anos de acordo com o Relatório de Avaliação Global do IPBES sobre Biodiversidade e Serviços Ecossistêmicos (2019).

Essas tendências negativas se alastram por todo território brasileiro, notadamente, sobre a biodiversidade Amazônica, a qual sofre diariamente com a diminuição da sua variedade de espécies nativas da fauna e flora por consequência do desmatamento e exploração ilegal de recursos naturais. De acordo o Sistema de Alerta de Desmatamento- SAD (2020) houve um aumento de 10\% das florestas desmatadas na Amazônia Legal e essa degradação ambiental ao longo dos anos.

Tendo em vista que biodiversidade Amazônica é mundialmente conhecida, porém não é compreendida em suas particularidades. As mídias impressas, digitais e áudio visuais objetivam alcançar esse público com textos de DC. Revistas digitais e impressas como: Revista Ciência hoje, Revista Super Interessante, Revista Galileu, Revista Pesquisa FAPESP e Revista de Estudos Avançados da Universidade de São Paulo constituem uma iniciativa importante para a compreensão e aproximação do público com temas complexos. 
Figura 2 - Análise de revistas de DC que discutem biodiversidade

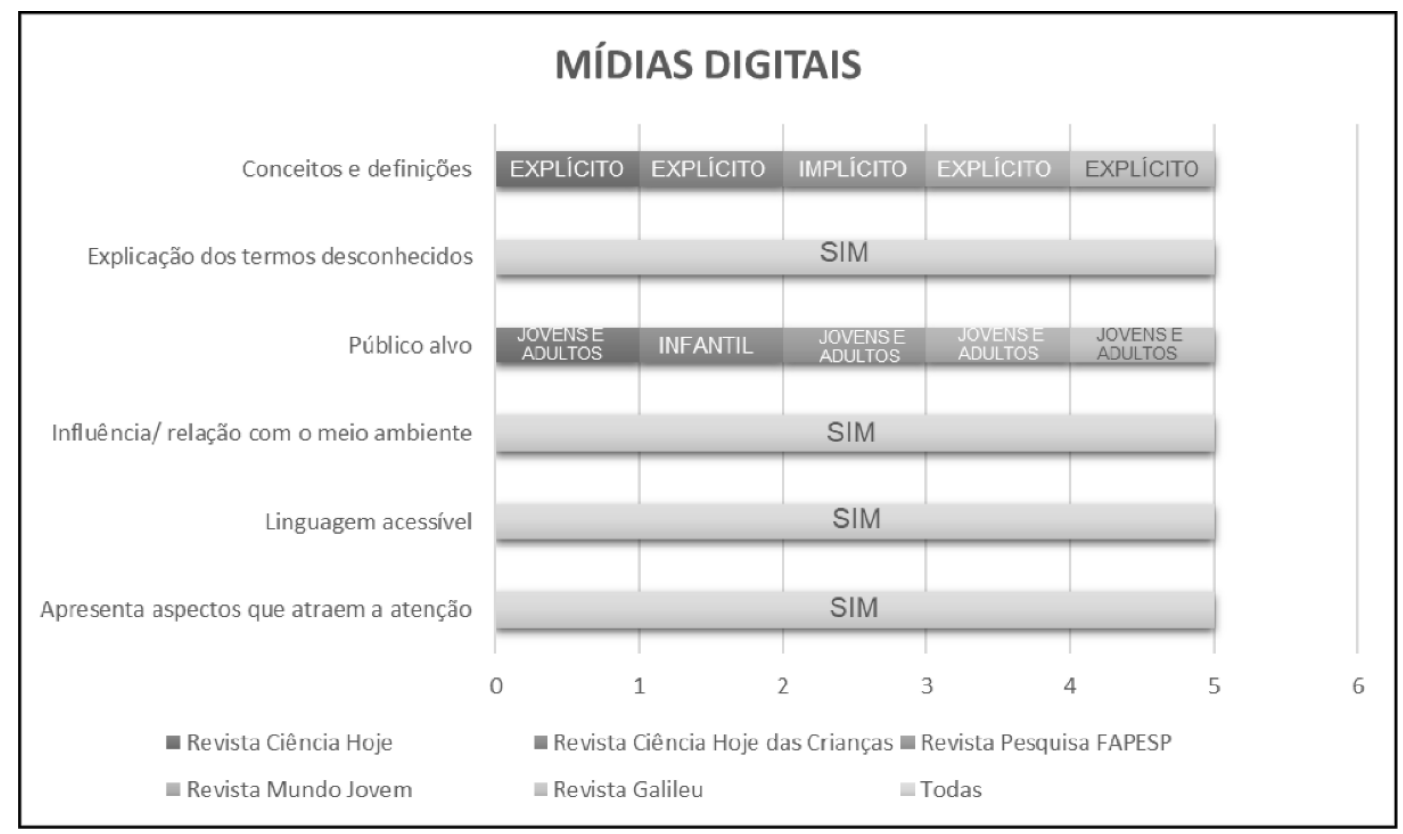

Fonte: Organização das autoras

Em geral, as revistas digitais apresentam uma versão impressa com o mesmo conteúdo encontrado na modalidade digital. Sendo comum encontra-las mais facilmente na versão digital. Todas as revistas apresentadas são encontradas gratuitamente, com linguagem acessível a todos os públicos e desenvolvendo temas atualizados relacionados a biodiversidade brasileira e amazônica.

Figura 3 - Website da revista ciência hoje

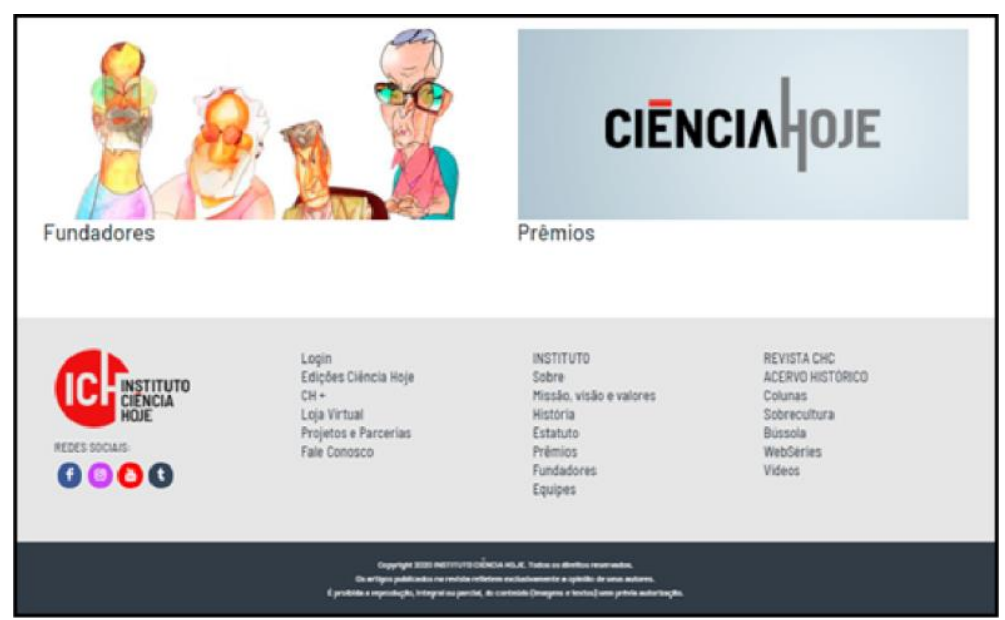

Fonte: Instituto ciência hoje (2021)

Nota: (https://cienciahoje.org.br/instituto/) 
A revista ciência hoje existe desde 1982. A ideia de divulgar temas científicos foi gestada pela Sociedade Brasileira para o Progresso da Ciência (SBPC) com a intencionalidade de trazer esses temas para uma discussão mais ampla e próxima da sociedade geral. Trata-se de "estabelecer uma interação eficiente para que a informação científica seja capaz de beneficiar a sociedade e seus cidadãos" (AMARAL; JULIANI, 2020, p. 6). Assim, diversos cientistas e pesquisadores passaram a dedicaremse a divulgação/popularização da ciência.

A divulgação científica diferencia-se da comunicação científica em diversos aspectos. A comunicação restringe-se a interação entre pesquisadores, com linguagem, códigos e meios de expressão específicos. A divulgação, também chamada de popularização ocupa-se de fazer a ponte entre os temas/resultados de pesquisas científicas com a sociedade. Nesta última a linguagem escrita, imagética, e simbólica está adaptada para ser compreendida, inclusive, por pessoas que não tenham formação científica em nível superior.

A revista ciência hoje é pioneira neste mercado. Anos mais tarde, em 1991, surgiu a "ciência hoje para crianças', com objetivos semelhantes, porém com layout e linguagem elaborado para atingir o público infanto-juvenil em idade escolar. A iniciativa vem a partir da compreensão que o caminho para transformação social perpassa por uma alfabetização e letramento científico que sustentem a tomada de decisão dos cidadãos.

Formar para a cidadania é formar pessoas que têm compreensão do próprio papel como cidadão do mundo; que respeitam e valorizam a diversidade; têm um entendimento de como o mundo funciona economicamente, politicamente, culturalmente, socialmente, tecnologicamente e ambientalmente; que são contrárias à injustiça social; que participam e contribuem com a comunidade de vários modos em nível local e global; que estão dispostas a agir para tornar o mundo um lugar mais igualitário e sustentável; e que assumem as responsabilidades de suas ações (CESCHIM; OLIVEIRA, 2018, p. 134).

Diante disso, o acesso a leituras de divulgação científica favorece a participação social em audiências públicas, por exemplo, com posicionamentos assertivos e cientificamente embasados. 
A Revista Ciência Hoje apresenta linguagem acessível voltada ao público juvenil e adultos. Entretanto, diferente das outras revistas ela apresenta preliminarmente os conceitos. E desenvolve amplamente o tema biodiversidade em seus textos de divulgação científica. A revista pode ser encontrada tanto na versão digital como na versão impressa, sendo parcialmente gratuita.

A abordagem do tema na revista se da com a utilização de conceitos bem definidos, dados oficiais e ilustrações com a finalidade de atrair a atenção de quem lê. Um diferencial encontrado na Revista Ciência Hoje é a possibilidade de ser utilizada no ensino infantil, pois a mesma apresenta edições voltadas ao público com idade escolar, em especial, no nível do fundamental maior ( $6^{\circ}$ ano ao $9^{\circ}$ ano).

A revista Pesquisa FAPESP é organizada pela Fundação de Amparo à Pesquisa do Estado de São Paulo. Teve sua primeira edição no ano de 1999 e, tem por objetivo principal propalar os resultados de pesquisas científicas nacionais, sem desmerece novidades internacionais.

Figura 4 - Website da revista pesquisa FAPESP

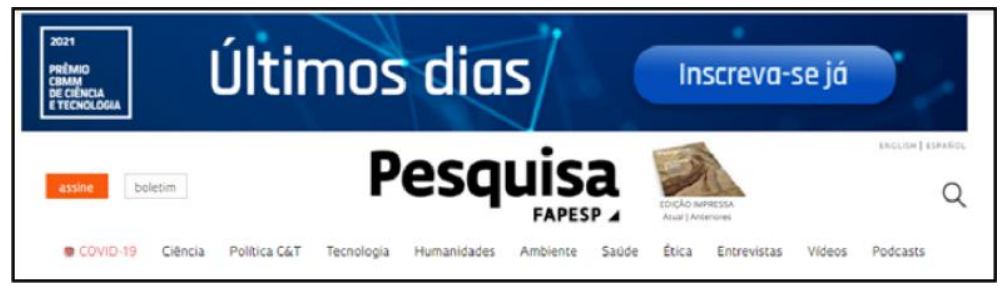

Fonte: Revista FAPESP (2021)

Nota: https://revistapesquisa.fapesp.br

A revista possui um perfil jornalístico, direcionado para um público mais adulto. Por isso, considera-se que ela comunica e divulga temas científicos em uma linguagem mais acessível socialmente, porém sem a ampla contemplação didática observada em outras revistas. Para Albagui (1996, p. 399).

Jornalismo científico pode ser definido como um processo social baseado em uma frequente e oportuna relação entre organizações formais (estabelecimentos/redes de editores) e comunidades (público/espectadores) que tem lugar através da mídia (jornais/revistas/rádio/TV/cinema) e que circula 
informação atualizada sobre a natureza científica e tecnológica, de acordo com variados graus de interesse e expectativa (universos culturais e ideológicos).

O material veiculado na revista Pesquisa FAPESP possui natureza informativa e, opinativo também. Por isso, os textos são divulgados por meio de notícias, reportagens, notas, reportagens, crônicas, dentre outras modalidades textuais. Desde 1995 ela é distribuída gratuitamente para pesquisadores associados. E hoje todos os conteúdos são abertos e gratuitos.

Em realidade, apesar das análises alcançarem materiais contemporâneos, as práticas desse tipo de atividade remontam aos séculos XVI/XVII. Em sua origem, tinha por objetivo reagir a censura a atividade científica ocasionada, principalmente, pela igreja. Desde este tempo prezava-se por uma linguagem acessível a todos.

Em 2002 a revista de divulgação científica da FAPESP passou a ser comercializada em bancas de jornais e revistas em todo país. E hoje, o site da revista dispõe gratuitamente todos os textos e materiais que produzidos. Ademais, o conhecimento popularizado circula nas diversas redes sociais da revista e, com isso atinge um público maior de pessoas.

A Revista Galileu começou a ser veiculada em 1991 pela editora Globo. A finalidade era a comunicação midiática para divulgar assuntos que envolvem ciência e tecnologia com ênfase no cotidiano. A revista possui uma plataforma digital com seu perfil de público jovem e adultos.

A editora globo conta com renomados profissionais brasileiros e mundiais. Seu viés jornalístico é pautado nos assuntos mais discutidos no momento da publicação. Isto varia de acordo com o momento histórico, com o mercado e, relevância das produções acadêmicas. Seu layout se apresenta com títulos e ilustrações em destaque, pensados para prenderem a atenção do leitor (LACOMBE, 2020).

A Revista Mundo Jovem foi inaugurada em 1967 com o objetivo de inovar na divulgação cientifica ao fazer uso de uma linguagem simples e direta. Hoje, 
encontra-se somente em plataforma digital, mas já teve tiragens impressas. Um diferencial é a priorização da interatividade entre professores, alunos e curiosos. O site da revista disponibiliza fóruns de mensagens e promove grupos de estudos formados por jovens leitores.

A revista é editada desde sua inauguração pela PUC-RS e, permanece até os dias atuais. Entretanto, as publicações voltadas para o tema biodiversidade amazônica foi identificado pela última vez no ano de 2011. O material veiculado na revista possui natureza informativa para o público juvenil. A linguagem textual são artigos e crônicas gratuitas.

Há um investimento midiático da revista pesquisa da FAPESP em vídeos e podcast, tendencia para comunicação atual. E esta não é uma movimentação solitária, pois as revistas de DC tem migrado para as mídias de áudio e visuais em virtude da ampliação de mercado para este tipo de comunicação e interação. Diante da dinâmica social atual, pode-se dizer que as revistas que não investem em meios de divulgação digitais e redes sociais, tendem a desaparecer ou diminuir seu alcance de público.

Figura 5 - Podcasts FAPESP

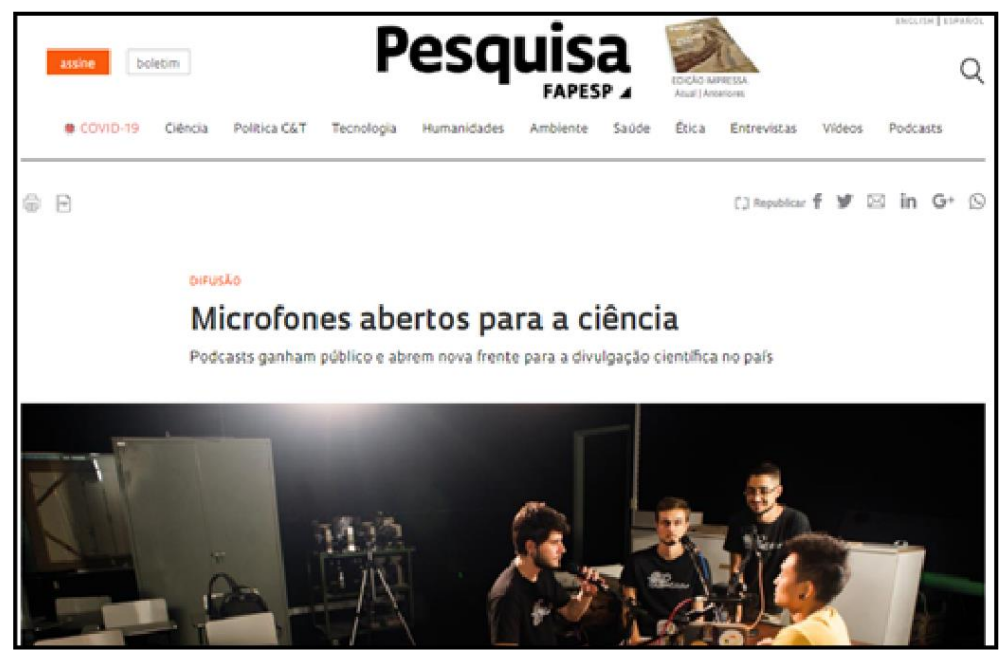

Fonte: CHAVES, 2019

Nota: https://revistapesquisa.fapesp.br/microfones-abertos-para-a-ciencia/ 
Tabela 2 - Divulgação cientifica em plataformas digitais

\begin{tabular}{|c|c|}
\hline Áudio-visual & Podcast \\
\hline $\begin{array}{l}\text { Título do material: Canal do Pirulla } \\
\text { Modalidade: Áudio visual } \\
\text { Link: } \\
\text { https://www.youtube.com/channel/UCdGpd0gNn38UK } \\
\text { woncZd9rmA }\end{array}$ & $\begin{array}{l}\text { Título do material: Podcast Sintonia } \\
\text { Ambiental } \\
\text { Modalidade: Áudio digital } \\
\text { Link: } \\
\text { https://www.radio.ufop.br/podcasts/meio- } \\
\text { ambiente-0 }\end{array}$ \\
\hline $\begin{array}{l}\text { Título do material: Canal Bio's fera } \\
\text { Modalidade: Áudio visual }\end{array}$ & Título do material: Podcast FAPESP \\
\hline $\begin{array}{l}\text { Link: https://www.youtube.com/channel/UCAgglgIRD- } \\
\text { FKW4_q9FK2zEw }\end{array}$ & $\begin{array}{l}\text { Modalidade: Áudio Digital } \\
\text { Link: }\end{array}$ \\
\hline $\begin{array}{l}\text { Título do material: Canal bláblálogia } \\
\text { Modalidade: Áudio visual } \\
\text { Link: } \\
\text { https://www.youtube.com/c/BI\%C3\%A1BI\%C3\%A1Logi } \\
\text { a/videos }\end{array}$ & $\begin{array}{l}\text { https://revistapesquisa.fapesp.br/multimidi } \\
\text { /podcasts/ } \\
\text { Tabela 9: Ficha de análise do Podcast } \\
\text { FAPESP como mídia de DC áudio digital. }\end{array}$ \\
\hline 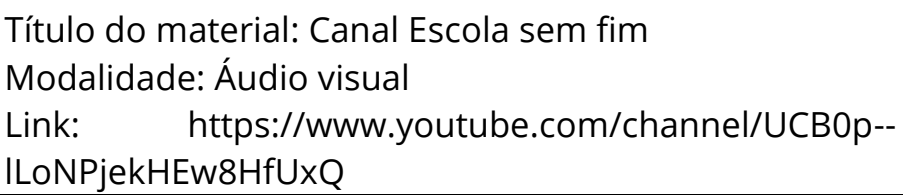 & \\
\hline
\end{tabular}

Fonte: Organização das autoras

A necessidade de comunicação entre pessoas de diferentes seguimentos sociais, associada a urgência da divulgação de temas socio científicos tem apontado para o uso de diferentes mídias digitais pela academia e agências de fomento. Nesse contexto, mídias como o rádio, tem tomado contornos de transformação por meio da internet (MARQUES, 2019).

O rádio que, outrora, encantava o público geral com conteúdo jornalístico e, entretenimento artístico e esportivo, hoje abre espaço para os podcasts. Relevante por alcançar públicos de diferentes faixas etárias, ser de acesso facilitado e, por vezes, gratuito. Esse veículo de informação tem crescido no cenário brasileiro, diante do estilo de vida atual, voltado para o trabalho e, com cada vez menos, espaço para atividades de laser ou entretenimento com horários fixos.

Para Lages (2018, p. 1) “Podcast é um programa de áudio, geralmente dividido em uma série de episódios, que pode ser baixado ou ouvido online". Este termo, que já não é novidade para muitos, tem sua origem no ano de 2004 , resultado da 
união de iPod com e broadcast (transmissão). Por meio dele, basta estar conectado a internet para acessar plataformas, aplicativos e programas de distribuição de conteúdo público. E por vezes, o material, inicialmente, veiculado on line, posteriormente fica disponível off line, e, pode ser ouvido repetidas vezes por meio de Downloads.

A pesquisa analisou os materiais descritos no quadro 2 em relação ao tema biodiversidade amazônica. O podcast é considerado um meio de difusão de conhecimento cientifico inovador, pois apresenta diversas possibilidades de formatos, linguagens e públicos.

Figura 6 - Podcast sobre biodiversidade

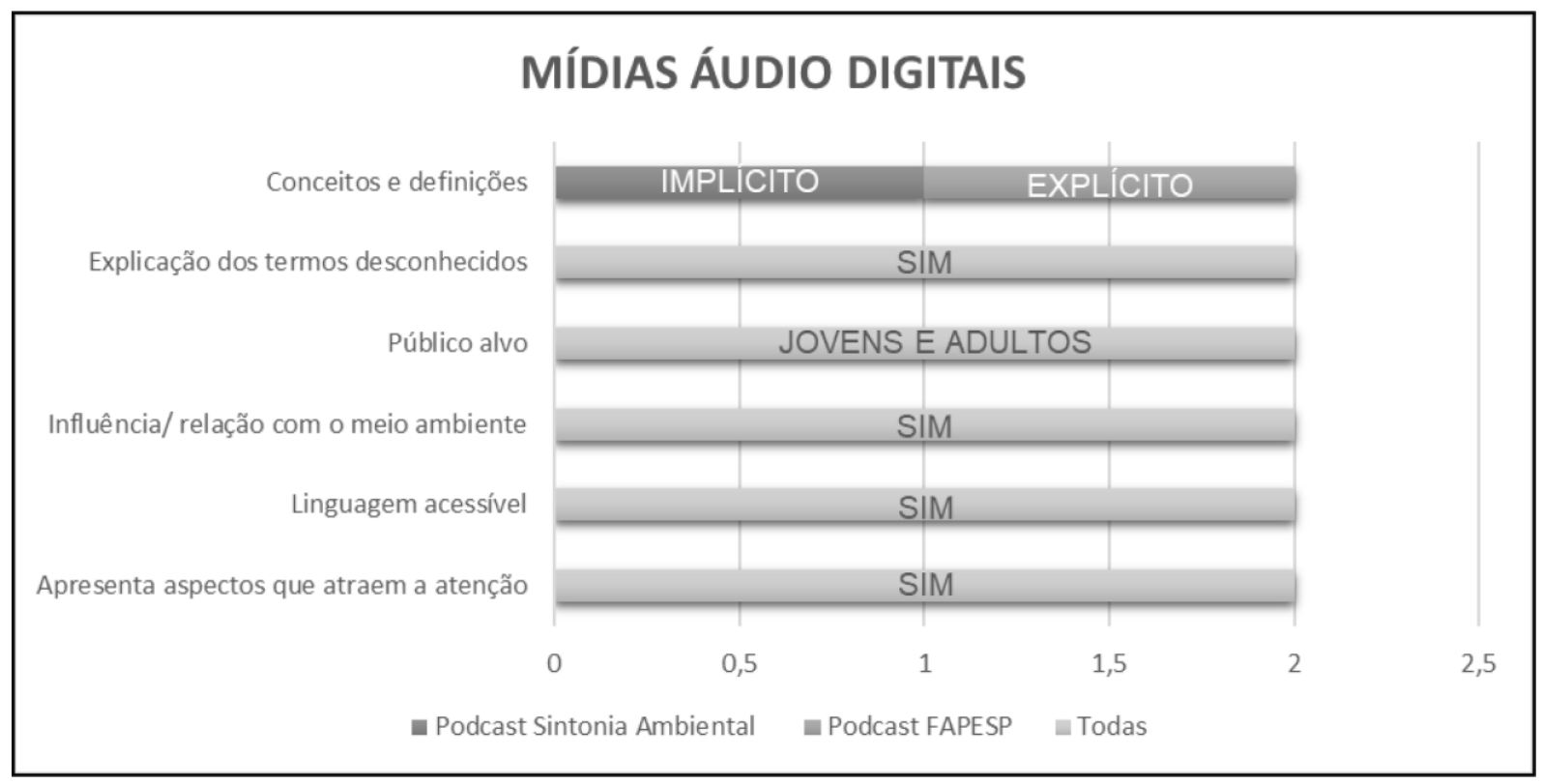

Fonte: Organização das autoras

O Podcast da Revista Pesquisa FAPESP desenvolve o tema biodiversidade através de entrevistas com profissionais especializados no assunto. Nesse material o conceito encontra-se implícito requerendo desta forma conhecimentos prévios sobre o assunto. Porém, a linguagem utilizada é acessível para o público juvenil e adultos. Jacobsen $(2019$, p. 5) afirma que a: Também observou que dois terços deles são apresentados por pesquisadores. 
Os podcasts há tempos se disseminaram nos Estados Unidos, onde há programas científicos muito consagrados, caso do Startalk [...].

A complexidade de conceitos e interações sociais que envolvem a biodiversidade necessita de um meio de divulgação que alcance o meio, e, os diferentes públicos interessados. Por isso, os pesquisadores compromissados com a dimensão cidadã da ciência, enquanto atividade social, tem adaptando-se no uso das mídias áudio digitais para alcançar, inclusive, pessoas leigas, com pouca afinidade com temas científicos. Neste contexto, merece destaque o sistema UFOP de Rádio com ampla seleção de podcast denominada Sintonia Ambiental.

Os materiais analisados com natureza áudio visual revelam ainda, outro meio de comunicação/interação com a sociedade geral que tem sido amplamente explorado por interessados em DC, são os canais da plataforma YouTube. Em especial nos dias atuais a sociedade necessita de informação e, a internet é a principal fonte de acesso para a sociedade em geral.

\begin{abstract}
A escolha do YouTube em muito se deve por ser a maior plataforma de exibição e compartilhamento de vídeos na internet, pela facilidade em atingir um grande número de usuários, além de possibilitar que os envolvidos tenham uma crescente visibilidade (SILVA NETO, 2018, p. 3).
\end{abstract}

Percebe-se que o vídeo enquanto instrumento de divulgação científica, mostra-se importante para alcançar públicos diversos, com uma linguagem mais comum a todos. É eficaz para abordagem de temas complexos, pois há mecanismos de produção que se afastam da monotonia, geralmente associada a longas explicações. O vídeo agrega uma linguagem dinâmica, ilustrativa que associada ao áudio dinamiza o potencial de fazer-se entender até para um público considerado leigo.

A nova versão da Web trouxe de fato consequências positivas. Com ela, os agentes da divulgação ampliaram-se e seus perfis diversificaram-se; as audiências hoje são maiores e mais distribuídas no globo do que nunca, e novos meios e plataformas permitem a manipulação de uma diversidade de conteúdos e linguagens anteriormente inimaginável. Porém, esta mesma democratização da autoria, aliada ao anonimato promovido nas redes, também trouxe a disseminação de desinformações científicas e a ultra-polarização de 
discussões científicas social, política e religiosamente sensíveis (VELHO, 2019, p. 30).

Canais de DC presentes no YouTube, tais como: Pirulla, bláblálogia, Bio's fera e escola sem fim, apresentam conteúdos relevantes sobre a biodiversidade brasileira e amazônica de forma divertida e atrativa. Considera-se essas mídias importantes para a popularização da ciência, uma vez que proporcionam essa aproximação da sociedade com o conhecimento científico.

\begin{abstract}
A evolução da sociedade, as mudanças no ambiente e o desenvolvimento da tecnologia afetam a forma como a comunicação se manifesta. Naturalmente, a internet e sua popularização também afetaram a forma de se comunicar, principalmente por facilitar de forma drástica o acesso à informação (SILVA NETO, 2018, p. 45).
\end{abstract}

Diante das mudanças de hábitos e meios de comunicação interpessoal, profissional e coletivo em decorrência, principalmente da globalização e uso mais amplo da rede mundial de computadores, internet, existe a necessidade das revistas de DC acompanharem tais transformações. O ritmo acelerado, sobretudo, das atividades urbanas, impôs a humanidade meios mais interativas de comunicação.

Figura 7 - Canais de divulgação cientifica no youtbe sobre biodiversidade

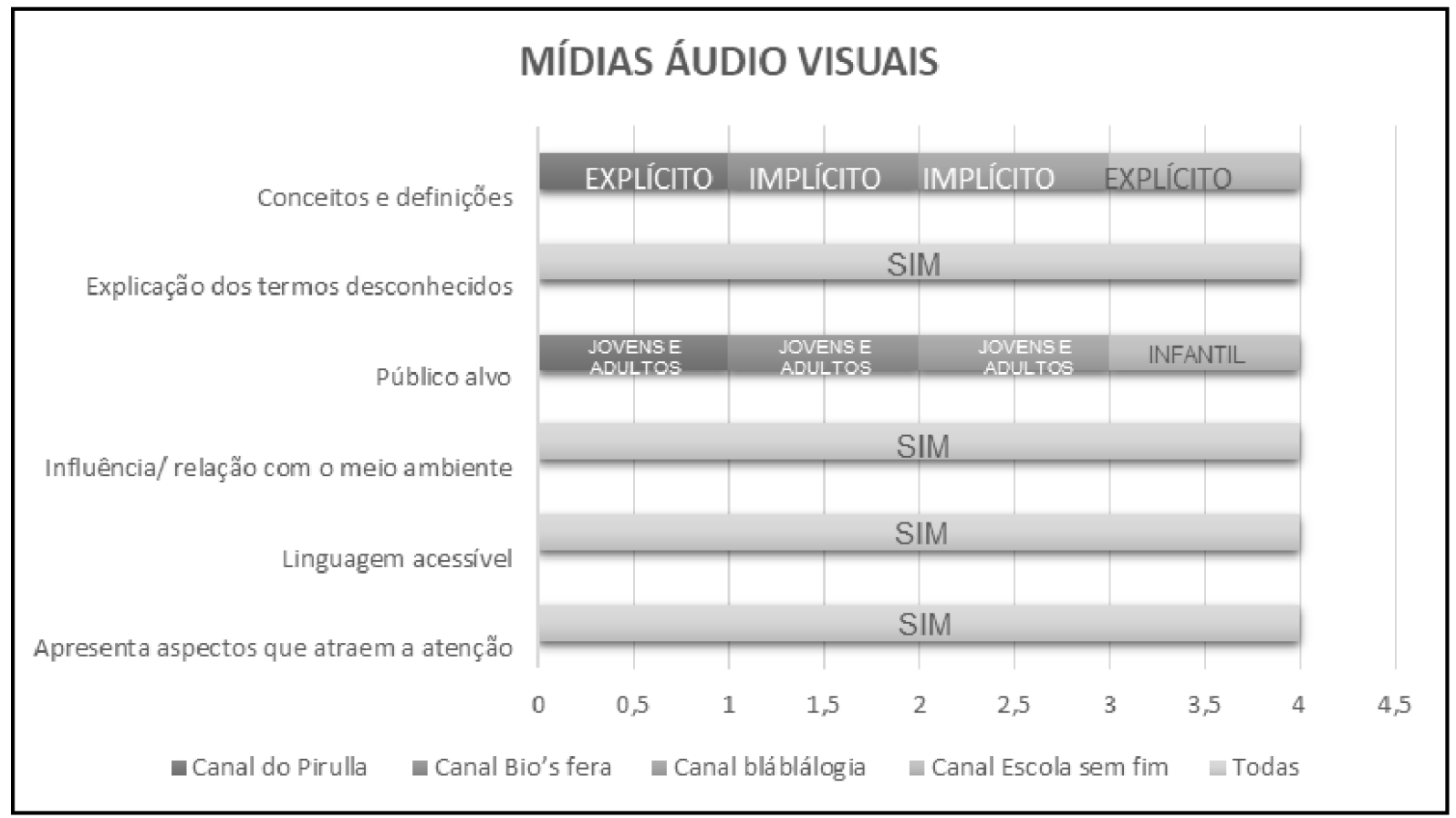

Fonte: Organização das autoras 
Werneck (2002, p. 81) ressalta que a informação e a transmissão do conhecimento são parte de um processo educativo e o brasileiro. A população geral ainda é pouco informada sobre o mundo da ciência, desconhece a realidade das atividades de pesquisadores/cientistas. E a questão da não gratuidade termina por afastar a sociedade do saber cientifico, resultando em uma grave lacuna cultural.

Na análise, o canal Bio'sfera apresentou-se como um material de DC voltado ao público juvenil e adultos que não apresenta preliminarmente os conceitos. Porém, desenvolve o tema em vídeos e lives bem explicativas utilizando dados oficiais. Esse material de mídia áudio visual também possui linguagem acessível. Expõe ainda ilustrações digitais com aspectos que atraem a atenção para o tema abordado. Cumprindo assim seu objetivo de divulgação científica durante seus sete (7) anos na plataforma YouTube.

Os canais de DC no YouTube tem alcançado resultados expressivos. Por exemplo, o projeto Science vlog Brasil já reúne cerca de 48 canas de DC. E apresenta aproximadamente, 8 milhões de inscritos no YouTube e mais de 500 milhões de visualizações. Isto ratifica o uso dessa mídia como veículo de promoção da popularização do conhecimento científico.

\section{CONSIDERAÇÕES FINAIS}

Divulgar conteúdos científicos tornando-os acessíveis para sociedade geral é uma necessidade eminente. A pesquisa demonstrou que os meios de DC tem variado de acordo com as transformações sociais. Revistas de DC, que anteriormente só apresentavam versões impressas, tem se mantido no mercado ao abranger plataformas digitais. É o caso das revistas: Ciência Hoje, Pesquisa FAPESP, Galileu e Mundo Jovem. 
O uso de mídias de áudio (PodCast) e áudio visuais (Canais no YouTube) tem crescido e, revelado um espaço de veiculação de informações sobre ciência que alcança um público mais jovem e, por vezes, sem letramento científico.

A utilização desses materiais apresenta valiosa contribuição no ensino de ciência e na formação de futuros cidadãos. Entretanto as estratégias de abordagens de conceitos, explicação dos termos desconhecidos, e linguagem variam de acordo com o público a que se direciona, notadamente quando o tema é biodiversidade.

\section{AGRADECIMENTOS}

Agradecimentos a UFAM pela bolsa de Iniciação Científica concedida.

\section{REFERÊNCIAS}

ALBAGLI, S. Divulgação científica: informação científica para a cidadania?. Ci. Inf. Brasília, v. 25, n. 3, p. 396-404, 1996.

AMARAL, F. V.; JULIANI, J. P. Diálogo entre comunicação e divulgação científica: reflexões para o desenvolvimento de habilidades em competência crítica da informação. Biblos: Revista do Instituto de Ciências Humanas e da Informação. Rio Grande, 2020.

BATISTELE, M. C. B. Análise de características de textos de divulgação científica da revista Minas Faz Ciência: possibilidades para o ensino de química. Universidade Federal de Itajubá Programa de Pós-graduação em Ensino de Ciências. Itajubá, 2016.

BAZZUL. J. A Educação em Ciências precisa de manifestos. Caderno Brasileiro de Ensino de Física, v. 37, n. 3, p 1173- 1192, dez. 2020.

BLUM, M. S. R.; DIAS, M. S. L.; Domingos Leite Lima Filho. Algumas considerações sobre a função da consciência a partir das Propagandas da reforma do ensino médio. Contexto \& Educação, Editora Unijuí, jan./abr. 2021.

BRASIL. Ministério do Meio Ambiente. Secretaria de Biodiversidade e Florestas. Convenção sobre Diversidade Biológica - CDB. Brasília - DF, 2000. 30 p.

BUENO, W. C. B. Comunicação científica e divulgação científica: aproximações e rupturas conceituais. Inf. Inf., Londrina, v. 15, n. esp, p. 1 - 12, 2010.

BUENO, Wilson da Costa. Jornalismo científico: revisitando o conceito. In: VICTOR, Cilene. 
CALDAS, Graça; BORTOLIERO, Simone. (Org.). Jornalismo científico e desenvolvimento sustentável. São Paulo: All Print, 2009. p.157-78.

CAPOZOLI, U. A divulgação e o pulo do gato. In: MASSARANI, L. et al. (Org.) Ciência e público: caminhos da divulgação científica no Brasil. Rio de Janeiro: Casa da Ciência - Centro Cultural de Ciência e Tecnologia da Universidade Federal do Rio de Janeiro. Fórum de Ciência e Cultura, 2002, p. 121-132.

CARVALHO W. L. P.; ORQUIZA-DE-CARVALHO, L. M. Educação para o Entendimento da População sobre Ciência e a Responsabilidade Científica: Reflexões em Meio a uma Pandemia. Ciência \& Educação, Bauru, v. 26, e20000, 2020.

CCST - INPE, 2019, Relatório de Avaliação Global do IPBES: Biodiversidade e Serviços Ecossistêmicos.

CELLARD, A. A análise documental. In: POUPART, J. et al. A pesquisa qualitativa: enfoques epistemológicos e metodológicos. Petrópolis, Vozes, 2008.

CESCHIM, B.; OLIVEIRA, T. B. Transgênicos, letramento científico e cidadania. Revista brasileira Ensino Ciências Tecnologia, Ponta Grossa, 2018.

CONCEIÇÃO, V. A. S; CHAGAS, A. M. O pesquisador e a divulgação científica em contexto de cibercultura e inteligência artificial. Universidade Tiradentes. Sergipe, 2020.

DUBRULL, D. S.; MAIA, E. D. Processo de produção de exposições em um museu de ciências: o MAST como exemplo. Ensaio- Pesquisa em Educação e Ciências. Belo Horizonte, v. 3, 2020.

FRANÇA, A. de A. Divulgação Científica no Brasil: espaços de interatividade na Web. Dissertação de mestrado em Ciência, Tecnologia e Sociedade da Universidade Federal de São Carlos-UFSCar, São Carlos, 2015.

GARCIA, J. C. R.; SOUSA, M.R.F. Cultura digital: odisseia da tecnologia e da ciência. Porto Alegre, 2011.

HOFFMANN, A. Infâncias, cultura visual e consumo: reflexões de pesquisas. Cad. Cedes: Campinas, v. 41, n. 113, p.56-64, jan. - abr., 2021.

IMAZON. SAD, sistema de alerta de desmatamento, 2020.

JACOBSEN, P. Podcasts abrem nova frente para a divulgação científica no país. Biblioteca Cetral UFRGS, 2019.

LÜDKE, M; ANDRÉ, M. A pesquisa em educação: abordagens qualitativas. 2Ed. Rio de Janeiro: EPU, 2014.

MALHORTA, N. Pesquisa de marketing: uma orientação aplicada. Porto Alegre: Bookman, 2019.

MARINELI, F. O terraplanismo e o apelo à experiência pessoal como critério epistemológico. Caderno Brasileiro de Ensino de Física, v. 37, n. 3, p. 1173- 1192, dez. 2020. 
MASSARANI, L. Jornalismo científico na América Latina: registro histórico do Primeiro Seminário Interamericano realizado na região em 1962. Intercom - RBCC. São Paulo, v. 44, n. 1, p.273-285, jan./abr. 2021.

MELO, C. A. R.; CHAVES, P. E. E.; OLIVEIRA, L. F. S.; MACHADO, M. M.; FARIAS, F. M. Ciência no velho oeste: 0 uso de um podcast na divulgação científica. Anais do $10^{\circ}$ Salão Internacional de Ensino, Pesquisa e Extensão - SIEPE, Universidade Federal do Pampa, 2018.

MOHR, A. A saúde na escola: análise de livros didáticos de $1^{\text {a }}$ a $4^{\text {a }}$ serie. Cadernos de pesquisa, v.94, p. 50-57. 1995.

MOREIRA, I. Novo canal de divulgação científica chega ao Youtube. Revista Galileu, 2016.

OLIVEIRA, Edilene Mafra Mendes de. A divulgação científica radiofônica em tempos de Internet: um estudo das adaptações do Rádio com Ciência ao ambiente da web. 2011. 193 f. Dissertação (Mestrado em Ciências da Comunicação) - Universidade Federal do Amazonas, Manaus, 2011.

OLIVEIRA, G. M.; TOCANTINS; WIGGERS, I. D. Infância e mídias digitais: histórias de Crianças e adolescentes sobre seus cotidianos. Cad. Cedes: Campinas, v. 41, n. 113, p.76-83, jan. - abr., 2021.

ORGANIZAÇÃO DAS NAÇÕES UNIDAS, 1992. Protocolo de Biossegurança: Convenção sobre a Biodiversidade, documento resultante da II Conferência das Nações Unidas sobre Meio Ambiente - Eco92.

PIVORO, G. F.; JÚNIOR, G.G. O ataque organizado à ciência como forma de manipulação: do aquecimento global ao corona vírus. Caderno Brasileiro de Ensino de Física, v. 37, n. 3, p. 1074-1098, dez. 2020.

PORTO, C.; OLIVEIRA, K. E.; ROSA, F. Produção e difusão da Ciência na cibercultura narrativa em múltiplos olhares. Editora da UESC. Bahia, 2018.

REVISTA CIÊNCIA HOJE. A biodiversidade cabe na sala de aula?, 2019.

ROSA, B. M.; DIAS, M. S.; LIMA, F. D. Algumas considerações sobre a função da consciência a partir das Propagandas da reforma do ensino médio. Revista Contexto \& Educação, 36(113), 2021.

SILVA NETO, J. R. Alcance da divulgação por meio do YouTube: estudo de caso no canal Meteoro Brasil. Universidade Federal de Minas Gerais, 2018.

SILVA, P; RIBES, R. M. Por uma ética nas produções audivisuais na cibercultura: a Infância em vídeos virais. Cad. Cedes, Campinas, v. 41, n. 113, p.23-32, Jan. - Abr., 2021.

SOUZA, P. H. R.; ROCHA, M. B. Análise da linguagem de textos de divulgação científica em livros didáticos: contribuições para o ensino de biologia. Rio de Janeiro, 2017.

VELHO, R. M. G. A. O papel dos vídeos de ciência na divulgação científica: o caso do projeto Science vlogs Brasil. Universidade Estadual de Campinas, 2019. 
WERNECK, E. F. E por falar em ciência... No rádio! In: MASSARANI, L. et al. (Org.) Ciência e público: caminhos da divulgação científica no Brasil. Rio de Janeiro: Casa da Ciência - Centro Cultural de Ciência e Tecnologia da Universidade Federal do Rio de Janeiro. Fórum de Ciência e Cultura, 2002, p. 81.

WILSON, E. O Diversidade da Vida. Rio de Janeiro: Companhia das Letras, 1994, 447 p.

ZANDONA, M. F.; GIERING, M. E. A referenciação em vídeos do YouTube de divulgação científica: uma atividade sincrética. Revista Calidoscópio, 2016.

\section{Contribuição de autoria}

\section{1 - lara Maíra Moraes de Andrade}

Acadêmica de Licenciatura em Ciências Naturais, http://orcid.org/0000-0001-5948-7501• iaramaira13@hotmail.com Contribuição: Conceituação; Software; Validação; Análise Formal; Investigação; Recursos; Curadoria de dados; Escrita - Primeira Redação; Visualização de dados; Obtenção de Financiamento

\section{2 - Elizandra Rego de Vasconcelos:}

Doutora em Educação Científica e Tecnológica, https://orcid.org/0000-0002-9634-4523•elizandravasconcelos@ufam.edu.br Contribuição: Metodologia; Validação; Análise formal; Recursos; Escrita - Revisão e Edição; Visualização de dados; Supervisão; Administração do projeto

\section{Como citar este artigo}

ANDRADE, I. M. M.; VASCONCELOS, E. R. Biodiversidade amazônica em materiais de divulgação científica com ênfase para o ensino de Ciências. Revista Monografias Ambientais, Santa Maria, v. 21, e3, 2021. DOI 10.5902/2236130864274. Disponível em: https://doi.org/10.5902/2236130864274. Acesso em: dia mês abreviado. ano. 